\title{
Fetal Pulmonary Artery Doppler as Non Invasive Predictor for Lung Maturity in Diabetic Patients: Does it Help?
}

\author{
RASHA R. ABD ELHADY, M.D. \\ The Department of Obstetrics and Gynecology, Faculty of Medicine, Zagazig University
}

\begin{abstract}
Background: The utility of non invasive tests for lung maturity should be encouraged for better timing of delivery in the risky groups especially diabetic patients.

Aim of Study: To evaluate fetal pulmonary artery indices in Diabetic mothers near delivery and further changes in response to corticosteroid therapy.

Patients and Methods: Multi step study was done, step one (case-control study) includes: Assessment of Pulmonary Artery Indices in groups (A) normal in comparison to group (B) Diabetic mothers. Step two (cross sectional study) on the Diabetic group only to assess the impact of steroid exposure on Doppler indices. Step three: Follow them postnatal to reveal the best cutoff values predicting respiratory distress syndrome RDS in neonates.
\end{abstract}

Results: The pulmonary indices (PI, RI) are much higher in diabetic patients, However (AT/ET) is significantly lower in the same group \& marvelous improvement after steroid dose. The best cutoff value for AT/ET in predicting RDS (0.28) sensitivity, specificity \& accuracy $(81.3 \%, 96.5 \%$ \& $94 \%$ ) respectively.

Conclusions: Pulmonary artery indices are valuable and promising predictor for lung maturity in Diabetic patients.

Key Words: Pulmonary artery - Doppler - Lung maturity Corticosteroid.

\section{Introduction}

DIABETES mellitus represents 3-5\% of all pregnancies \& considered a significant cause of perinatal morbidity and mortality, impaired glycemic control was reported to delay the synthesis of phosphatidyl glycerol in diabetic pregnancies [1].

Insulin has 2 effects in surfactant biosynthesis. Although a very low doses of insulin increase surfactant biosynthesis, high doses decrease it which is seen evident in fetus of diabetic mother [2]. Such fetuses are liable to develop respiratory

Correspondence to: Dr. Rasha R. Abd Elhady, E-Mail: D.rashareda@gmail.com distress syndrome, Insulin administration postnatal or even in adults with surfactant deficiency improves the surfactant synthesis by improving the energy metabolism [2] .

The decision of delivery in diabetic mothers is always a challenge; fetuses experience hyperglycemia, hyper insulinaemia and hyperlipidemia resulting in altered surfactant lipid metabolism and impair lung maturity [2] .

Amniotic fluid sampling is the gold standard measure for fetal lung maturity. But, it harbors potential risks to the pregnancy PROM, placental abruption, preterm labor, fetomaternal haemorrhage and even fetal injury [3]

American College of Obstetricians and Gynecologists recommends non-invasive testing for fetal lung maturity (FLM) to minimize the risk which would be more acceptable to women [4]

Many sonographic non-invasive parameters were assessed in the literatures e.g (Placental maturity grading, Free floating particles in amniotic fluid, lung echogenecity, lung volume, intestinal indices, estimated fetal weight and epiphyseal ossification centers) but with debatable results $[5,6,7]$

Pulmonary artery Doppler was recommended by many authors as a useful predictor for FLM as the pulmonary arterial vascular resistance decreases with advancing GA [8]. Also neonates with RDS have increased pressure in their pulmonary vasculature, which decreases after treatment with artificial surfactant [9].

Glucocorticoids increase the enzymatic activity to increase surfactant lipid synthesis. Cortisol induces fetal lung fibroblasts to produce fibroblast pneumocyte factor which stimulates surfactant 
production in Type II cells, the increased production of cortisol in 30-32 weeks of gestation has been associated with the fetal lung maturation and surfactant production [10]. In the current study we try to study the pulmonary artery indices as a predictor for FLM in diabetic compared to normal mothers with parallel GA, try to explore the impact of steroid injection on improving the situation and try to get the best cutoff value of pulmonary artery Doppler indices for prediction of RDS.

\section{Patients and Methods}

Step one: A prospective case control study was done: The sample size was calculated to be 113 cases using open-Epi (CI 95\% \& study power $80 \%$ ), recruited from the attendee of the antenatal outpatient clinics of the Obstetrics and Gynecology Department at Zagazig University Hospitals, Egypt. From January to December 2020.

Participants were divided into two groups: Normal (control) group A $(\mathrm{n}=58)$ \& Diabetic (case) group $B(n=55)$. Eligibility criteria: Singleton pregnancies, GA (36-38 weeks) \& no major fetal anomalies, multi fetal pregnancies, maternal medical conditions, ruptured membranes or abnormal AF disorders.

Informed consent, history taking \& routine examinations were done for all candidates (in both groups). Routine Ultrasound examination was done using $2 \mathrm{D}$ voluson $\mathrm{p} 8$ ultrasound with $(3-5 \mathrm{MHz})$ convex transducer to get (fetal biometry, placenta, EFBW \& AF volume). The heart is examined in serial axial planes (4 chamber, outflow tracts \& three-vessel view). Pulmonary A. Doppler scan: At the RT. Outflow tract, with complete fetal rest, MPA should be followed until point midway between the valve and the pulmonary bifurcation (sample gate should adjust to $3 \mathrm{~mm} \&$ angle of insonation $<15^{\circ}$. Color gain \& scale were adapted for perfect flow display. The MPA Doppler waveform with its characteristic shape should be identified to differentiate it from ductus arteriosus waveform, the wave was traced manually 3 times and average measurements was taken.

Doppler indices in both groups include: Pulsatility index, resistance index \& At/Et \%. For obtaining AT/ET ratio: Time interval from ventricular systole begin to peak systolic (At) / time interval (begin to end) of the ventricular systole (Fig. 1) then the final data for both groups were recorded \& compared.

Step two: (Cross sectional study) was done on the Diabetic group ( $\mathrm{n}=50)$. FBS, 2-hour post pran- dial and $\mathrm{HbA} 1 \mathrm{C}$ were done to ensure the glycemic control for all participants. Corticosteroid course was given (two doses of $12 \mathrm{mg}$ betamethasone IM $24 \mathrm{~h}$ apart) $24-48 \mathrm{~h}$ later, all members underwent ultrasonography again to measure the post exposure values for pulmonary artery Doppler indices.

Step three: (Observational prospective) to follow all the Diabetic participant postnatal to pick the best cutoff values for pulmonary artery Doppler indices in prediction of RDS in this risky group, that will be diagnosed by at least 2 out of 3 points: (1) Evidences of Respiratory failure shortly postnatal \& increase oxygen requirement more than 24 hours. (2) Radiographic evidence of hyaline membrane diseases. (3) Response to exogenous pulmonary surfactant.

\section{Statistical analysis:}

Data were displayed as (mean \pm S.D.) Comparison of numerical variables was done using Student's $t$-test for independent samples. For correlation between multiple variables Pearson's moment correlation equation or Spearman's rank correlation equation (according to the data distribution) were used. Receiver operator curve was used to determine the optimal cutoff values. Tests considered statistically significant when $p$-values 0.05 . All statistical assessments were carried out using SPSS 15 program for Microsoft Windows (2006).

\section{Results}

The study was started with 58 patients in the normal group (A) and 55 patients in the Diabetic group (B) who met the eligibility criteria. However, later, 8 patients ${ }^{1 \text { st }}$ group $\& 5$ patients 2 nd group were excluded from the study some due to sudden delivery and others have difficult examination (due to current fetal position).

Finally, 100 participants in both groups (50 participants in each one) were used in the final analysis that reveal: No significant difference between the two groups in terms of maternal age, mean gestational age but a significant difference regarding maternal body mass index that was closely related to the diabetic group. As well known (Obesity is strongly associated factor) with subsequent significant increase in EFBW due to the anabolic effect of hyperinsulinemia (Table 1). There is a significant difference between both groups regarding the mean values of all pulmonary Doppler indices (Table 2), Spearman's correlation coefficient reveals a negative correlation between the GA and Doppler indices (PI, RI) \& positive correlation for (AT/ET ratio) in both groups with 
lower significance in Diabetic one (Table 3). There is a significant difference between the Doppler indices values pre \& post steroid injection specially (PI, RI \& AT/ET ratio) in Diabetic group (Table 4). Following those patients post natal PI and RI were significantly higher in neonates with RDS while AT/ET ratio had significantly lower values (Table 5) \& The receiver operating characteristic curve revealed that the best cutoff for (PI, RI \& AT/ET ratio) in prediction of neonatal RDS among Diabetic patients were $(2.2,0.76 \& 0.28)$ respectively with a great significance (Table 6).

Table (2): Comparison between both groups regarding pulmonary artery indices.

\begin{tabular}{|c|c|c|c|}
\hline \multirow[t]{2}{*}{ Parameter } & $\begin{array}{c}\text { Group A } \\
\text { (Normal, } \mathrm{n}=50)\end{array}$ & $\begin{array}{c}\text { Group B } \\
\text { (Diabetic, } n=50)\end{array}$ & $p$ \\
\hline & Mean \pm SD & Mean \pm SD & \\
\hline $\mathrm{S} / \mathrm{D}$ ratio & $6.79 \pm 0.15$ & $7.09 \pm 0.2$ & 0.256 \\
\hline $\mathrm{PI}(\mathrm{cm} / \mathrm{S})$ & $2.16 \pm 0.03$ & $2.96 \pm 0.03$ & $<0.01 *$ \\
\hline $\mathrm{RI}(\mathrm{cm} / \mathrm{S})$ & $0.75 \pm 0.02$ & $0.79 \pm 0.03$ & 0.063 \\
\hline AT/ET ratio & $0.31 \pm 0.05$ & $0.25 \pm 0.04$ & $<0.01 *$ \\
\hline
\end{tabular}

Table (4): Doppler Indices of Diabetic group ( $n=50)$ before $\&$ after Dexamethasone administration.

\begin{tabular}{|c|c|c|c|c|c|c|c|}
\hline \multirow{3}{*}{ Parameter } & \multicolumn{2}{|c|}{ Dexamethasone adminstration } & \multirow{3}{*}{$p$} & \multirow{3}{*}{$\begin{array}{l}\text { Parameter } \\
\text { Mean } \pm \text { SD }\end{array}$} & \multicolumn{2}{|c|}{ RDS development } & \multirow{3}{*}{$p$} \\
\hline & Before & After & & & Yes $(n=10)$ & No (40) & \\
\hline & Mean \pm SD & Mean \pm SD & & & Mean \pm SD & Mean \pm SD & \\
\hline S/D ratio & $7.09 \pm 0.2$ & $6.90 \pm 0.2$ & 0.271 & $\mathrm{~S} / \mathrm{D}$ ratio & $6.99 \pm 0.12$ & $6.86 \pm 0.12$ & 0.06 \\
\hline $\mathrm{PI}(\mathrm{cm} / \mathrm{S})$ & $2.96 \pm 0.03$ & $2.56 \pm 0.3$ & $<0.04 *$ & $\mathrm{PI}(\mathrm{cm} / \mathrm{S})$ & $2.24 \pm 0.06$ & $2.15 \pm 0.02$ & $<0.001 * *$ \\
\hline $\mathrm{RI}(\mathrm{cm} / \mathrm{S})$ & $0.79 \pm 0.03$ & $0.75 \pm 0.01$ & $0.031 *$ & $\mathrm{RI}(\mathrm{cm} / \mathrm{S})$ & $0.82 \pm 0.03$ & $0.75 \pm 0.02$ & $<0.001 * *$ \\
\hline AT/ET ratio & $0.25 \pm 0.04$ & $0.29 \pm 0.02$ & $<0.049 *$ & $\mathrm{AT} / \mathrm{ET}$ ratio & $0.24 \pm 0.05$ & $0.32 \pm 0.02$ & $<0.001 * *$ \\
\hline
\end{tabular}

Table (6): Validity of doppler indices in prediction of RDS in diabetic population.

\begin{tabular}{llccccccc}
\hline Parameter & Cutoff & AUC & Sensitivity & Specificity & PPV & NPV & Accuracy & Accuracy \\
\hline PI $(\mathrm{cm} / \mathrm{S})$ & $\geq 2.2$ & 0.86 & $83.2 \%$ & $76.1 \%$ & $41.2 \%$ & $94.1 \%$ & $77 \%$ & $<0.01 *$ \\
RI $(\mathrm{cm} / \mathrm{S})$ & $\geq 0.76$ & 0.90 & $82.3 \%$ & $77.3 \%$ & $44.8 \%$ & $95.5 \%$ & $78 \%$ & $<0.01 *$ \\
AT/ET ratio & $<0.28$ & 0.88 & $81.3 \%$ & $96.5 \%$ & $87.3 \%$ & $95.2 \%$ & $94 \%$ & $<0.001 * *$ \\
\hline
\end{tabular}

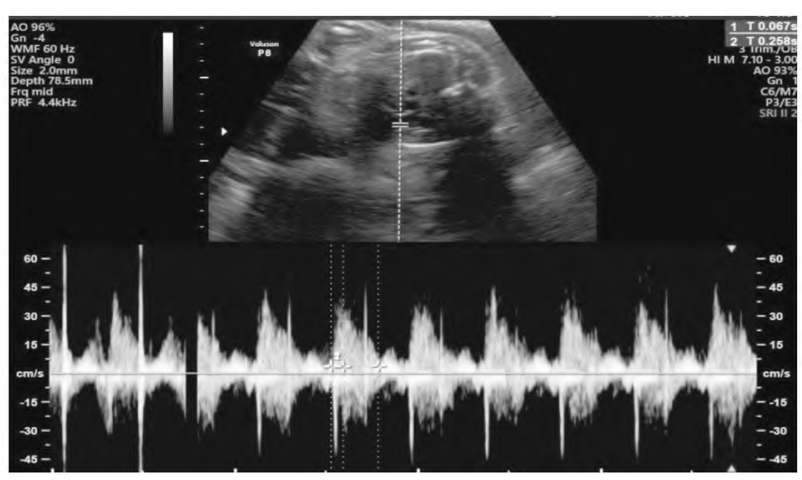

Fig. (1): Measurement of pulmonary artery Doppler indices: $\mathrm{AT}$ (T1) \& ET (T2) in normal fetus.
Table (1): Comparison between both groups regarding maternal $\&$ fetal parameters.

\begin{tabular}{llllll}
\hline \multirow{2}{*}{$\begin{array}{l}\text { Biometric } \\
\text { parameter }\end{array}$} & $\begin{array}{c}\text { Group A } \\
(\text { Normal, } \mathrm{n}=50)\end{array}$ & & $\begin{array}{c}\text { Group B } \\
\text { (Diabetic, } \mathrm{n}=50)\end{array}$ & $p$ \\
\cline { 2 - 2 } & Mean $\pm \mathrm{SD}$ & & Mean $\pm \mathrm{SD}$ & \\
\hline Maternal age & $27.65 \pm 3.8$ & & $28.33 \pm 4.5$ & 0.167 \\
$\begin{array}{c}\text { Maternal BMI } \\
\left(\mathrm{kg} / \mathrm{m}^{2}\right)\end{array}$ & $23.54 \pm 1.4$ & & $29.90 \pm 1.5$ & $<0.001 * *$ \\
Gestational age & $37.25 \pm 1.4$ & & $37.95 \pm 1.3$ & 0.31 \\
EFBW $(\mathrm{gm})$ & $3152.0 \pm 418$ & & $3800 \pm 489$ & $<0.001 * *$ \\
\hline
\end{tabular}

Table (3): Correlation between Pulmonary artery Doppler indices \& GA in study population.

\begin{tabular}{|c|c|c|c|c|}
\hline \multirow[t]{2}{*}{ Parameter } & \multicolumn{2}{|c|}{$\begin{array}{c}\text { Group A } \\
(\text { Normal, } \mathrm{n}=50)\end{array}$} & \multicolumn{2}{|c|}{$\begin{array}{c}\text { Group B } \\
\text { (Diabetic, } \mathrm{n}=50 \text { ) }\end{array}$} \\
\hline & $r$ & $p$ & $r$ & $p$ \\
\hline S/D ratio & -0.183 & 0.785 & -0.155 & 0.939 \\
\hline $\mathrm{PI}(\mathrm{cm} / \mathrm{S})$ & -0.023 & $<0.01 *$ & -0.006 & 0.130 \\
\hline $\mathrm{RI}(\mathrm{cm} / \mathrm{S})$ & -0.172 & 0.201 & -0.121 & 0.197 \\
\hline $\mathrm{AT} / \mathrm{ET}$ ratio & 0.105 & $<0.001 *$ & 0.104 & 0.136 \\
\hline
\end{tabular}

Table (5): Relation of pulmonary artery Doppler indices \& RDS in the Diabetic group.

\section{Discussion}

Being a significant metabolic disorder, Diabetes mellitus markedly affect the mother and her fetus who is commonly suffered from RDS once delivered.

In the current study, 100 cases were enrolled in two groups (normal \& diabetic) to assess the Role of pulmonary artery Doppler indices as non invasive alternative for fetal lung maturity testing in risky diabetic group, GA (36-38wk) was selected because the ensured lung maturity in this age is debatable. 
The results were shown that there is a negative correlation between the GA and Doppler indices (PI, RI) \& strong positive correlation for (AT/ET ratio) due to the expected continuous decrease in the vascular resistance of pulmonary circulation as the pregnancy advances. Diabetic group also shows the same correlation pattern but with weaker significance which also owing to its threatening effect that always endanger the lung maturity.

The current results are agreed with Moety et al., Chaoui et al., opinion who study the Doppler echocardiography of the main pulmonary arteries in the fetus. They suggested that mean pulmonary artery pressure decreases as pregnancy advances owing to increase the pulmonary vascular and, resulting in a gradual increase in pulmonary blood flow $[9,11]$

Pulmonary artery indices as indicator for fetal lung maturity was addressed in many literatures, Rasanen et al., noticed progressive decrease in the pulmonary artery impedance with advanced gestation [12]. This inverse relation between GA and vascular resistance could be caused by lumen expansion of the pulmonary vessels, improved vascular elasticity and evolving pulmonary angiogenesis that occur with advancing GA [13]. The same by Guan et al., who reported a strong correlation between GA and At, AT/ET, PSV, enddiastolic velocity and mean velocity in 288 normal fetuses ranged from 22 to 42 weeks gestation [8].

The current study showed a marvelous effect of the corticosteroid injection on improving the Pulmonary Doppler indices (PI, RI) and increase in AT \& (AT/ET) ratio, which could be nitric oxidemediated vasodilatation, which known to be induced by nitric oxide synthase enzyme secreted from the placenta $[\mathbf{1 4 , 1 5}]$

This idea was supported in many literatures, Ustunyurt et al., described significant decreases in the pulmonary artery PI \& RI at 24 and $48 \mathrm{~h}$ after administration of corticosteroid dose [16] Homeira et al., found a significant decrease in the pulmonary artery AT, but they do not state any difference in pulmonary artery AT/ET ratio [17]

In contrary, Lindsley et al., demonstrated that the pulmonary artery PI, RI, ET did not change in response to steroid therapy, However, pulmonary artery AT showed significant decreased after the administration, Actually their results could be participant dependant as the population studied is widely different [18]
Measurement of pulmonary artery indices might be used to predict neonatal RDS, as the anatomical and functional progress of fetal lung development increasing with gestational age coincide pattern change in the sonographic echogenicity of the lung, Furthermore fetal pulmonary artery flow velocity waveforms were found to change with increasing gestational age. As the lung is developing throughout pregnancy, the pulmonary vasculature also is getting progressive expansion. The total number of pulmonary arteries rises, the pulmonary arterial vascular resistance decreases [19].

The results reveal that neonates with RDS were experienced prenatal higher values for pulmonary Doppler indices (PI\&RI) with much lower AT/ET ratio. The issue could be explained by higher pulmonary vascular Resistance and lower blood flow in those fetuses. Similar to these results, Chaoui et al., Moety et al. \& Guan et al., noticed that the pulmonary artery AT \& AT/ET ratio increase as the pregnancy advances with lower values for the latter in neonates with RDS [8,9,11].

Notably, the increasing popularity of AT/ET ratio as a predictor for RDS, so in this study a calculation trial of a cutoff for AT/ET ratio was done that reveals value $<0.28$ has a sensitivity $81.3 \%$, specificity $96.5 \%$ \& significant Accuracy $94 \%$. These data was comparable to the results of Moety et al., who put a cutoff for (AT/ET 0.305) $\&$ Schenone et al., (cutoff 0.314) but with much lower Accuracy (sensitivity $76.4 \%$ specificity of $91.6 \%$ \& sensitivity $73 \%$ and Specificity $93 \%$ ) respectively $[\mathbf{9 , 2 0 ]}$.

\section{Conclusion:}

The current study recommends pulmonary artery Doppler indices as a practical, non invasive tool to judge on the fetal lung maturity approaching delivery specifically in risky groups as diabetic patient. Fetuses with AT/ET below cutoff (0.28) should be delivered in well equipped centers in anticipation of the risk of RDS.

\section{Ethical approval:}

The study has an approval from the institutional review board Faculty of Medicine, Zagazig University \& was done according to the Declaration Helsinki [21].

\section{References}

1- GABBE S. and GRAVES C.: Management of diabetes mellitus complicating pregnancy. Obstet. Gynecol., 102 (4): 857-868, 2015.

2- HONIDEN S. and GONG M.: Diabetes, insulin, and development of acute lung injury, Crit Care Med., 372455, 2009. 
3- GORDON M.C., NARULA K., O. SHAUGHNESSY R and BARTH Jr. W.H.: Complications of the third trimester amniocentesis using contionous ultrasound guidance. Obstet. Gynecol., 99 (2): 255, 2014.

4- American College of Obstetricians and Gynecologists: ACOG Practice Bulletin No. 97: Fetal lung maturity. Obstetrics and Gynecology, 112: 717-26, 2008.

5- PIAZZE J.J., ANCESSHI M.M., PICONE G., CEREKIA A., LA TORRE R. and COSMI E.V.: Association between maternal fetal Doppler velocimetry and fetal lung maturity. J. Perinat Med., 31 (6): 484, 2010.

6- DETER R.L., HADLOCK F.P. and CAROLLO B.R.: Ultrasonically determined menstrual age as an indicator of fetal lung maturity. J. Clin. Ultrasound, 10 (4): 153 7, 1982.

7- TABSH K.M.: Correlation of ultrasonic epiphyseal centers and the lecithin: Sphingomyelin ratio. Obstet. Gynecol., 64 (1): 92-6, 1984.

8- GUAN Y., LI S., LUO G., et al.: The role of Doppler waveforms in the fetal main pulmonary artery in the prediction of neonatal respiratory distress syndrome. J. Clin. Ultrasound, 43: 375-383, 2014.

9- MOETY G., GAAFAR H. and EL RIFAI N.: Can fetal pulmonary artery Doppler indices predict neonatal respiratory distress syndrome? J. Perinatol., 35: 1015-9, 2015.

10- SKOLL A., BOUTIN A., BUJOLD E., et al.: Antenatal corticosteroid therapy for improving neonatal outcomes, J. Obstet. Gynaecol., 40 (9): 1219-1239, 2018.

11- CHAOUI R., TADDEI F., RIZZO G., BAST C. and BOLLMANN R.: Doppler echocardiography of the main stems of the pulmonary arteries in the normal human fetus. Ultrasound Obstet. Gynecol., 11: 173-179, 1998.

12- RASANEN J., HUHTA J.C., WEINER S., WOOD D.C. and LUDOMIRSKI A.: Fetal branch pulmonary arterial vascular impedance during the second half of pregnancy. Am. J. Obstet. Gynecol., 174: 1441-1449, 1996.

13- GRENACHE D.G. and GRONOWSKI A.M.: Fetal lung maturity. Clin. Biochem., 39: 1-10, 2006.
14-KOREBRITS C., YU D.H., RAMIREZ M.M., MARINONI E., BOCKING A.D. and CHALLIS J.R.: Antenatal glucocorticoid administration increases corticotrophinreleasing hormone in maternal plasma. Br. J. Obstet. Gynaecol., 105 (5): 556-61, 1998.

15- CLIFTON V.L., READ M.A., LEITCH I.M., GILES W.B., BOURA A.L., ROBINSON P.J. and SMITH R.: Corticotropin-releasing hormone-induced vasodilatation in the human fetalplacental circulation: Involvement of the nitric oxide-cyclic guanosine 3,5-monophosphate-mediated pathway. J. Clin. Endocrinol. Metab., 80 (10): 2888-93, 1995.

16- USTUNYURT O.B., USTUNYURT E., KORKMAZER E., ALTUG N., BILGE U. and DANISMAN N.: The effect of maternal betamethasone administration on Doppler flow velocity parameters of the fetal branch pulmonary artery. Ultrasound Obstet. Gynecol., 34 (6): 489-91, 2014.

17- HOMEIRA V., FAHIMEH K., BAGHBAHADORANI, NASRIN A., MARYAM K., AZAM F., SHOHREH R., MARJAN Z. and KHADIJE B.: The impact of betamethasone on fetal pulmonary, umbilical and middle cerebral artery Doppler velocimetry and its relationship with neonatal respiratory distress syndrome BMC Pregnancy and Childbirth, 21: 188, 2021.

18- LINDSLEY W., HALE R., SPEAR A., ADUSUMALLI J., SINGH J., DE STEFANO K. and HAERI S.: Does corticosteroid therapy impact fetal pulmonary artery blood flow in women at risk for preterm birth? Med. Ultrason., 17 (3): 280-3, 2015.

19- CHAGUI R., TADDEI F., RIZZO G., BAST C., LENZ F. and BOLLMANN R.: Doppler echocardiography of the main stems of the pulmonary arteries in the normal human fetus . Ultrasound Obstet. Gynecol., 11 (3): 173, 2013.

20- SCHENONE M.H., SAMSON J.E., JENKINS L., SUHAG A. and MARI G.: Predicting fetal lung maturity using the fetal pulmonary artery Doppler wave acceleration/ejection time ratio. Fetal Diagn Ther., 36: 208-214, 2014.

21- Declaration of Helsinki (1964): BMJ, 313: 1448, 1996. 


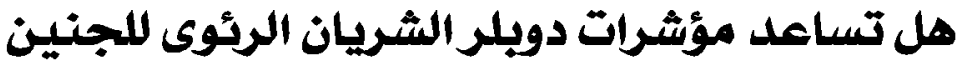

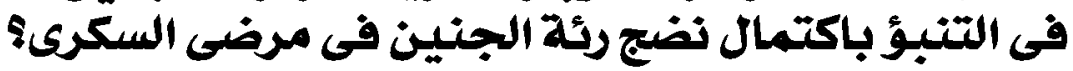

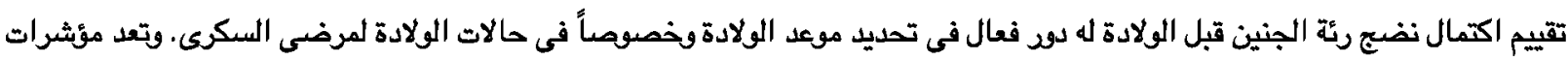

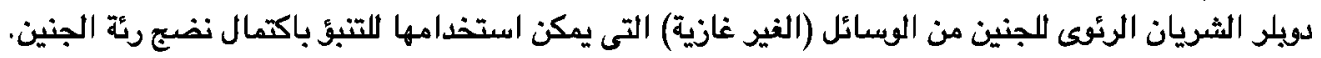

الهدف من الدراسة: قياس معدل تدفق الدم خلال الثريان الرئوى الجنين فكلما زاد العمر الرحمى الجنين زاد تدفق الدم وقلت مقاومة

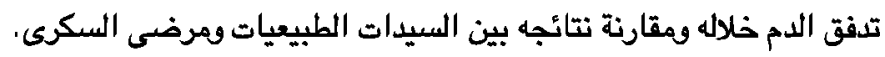

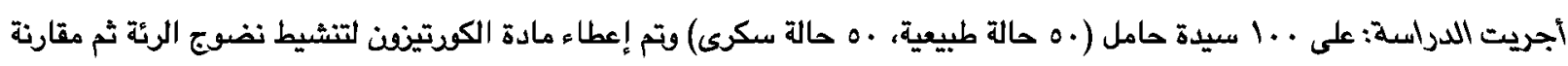

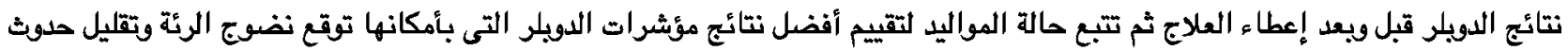
صعوبة التفس فى حديثى الولادة.

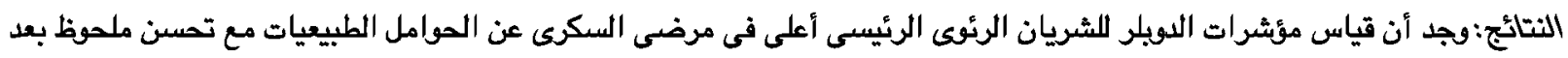

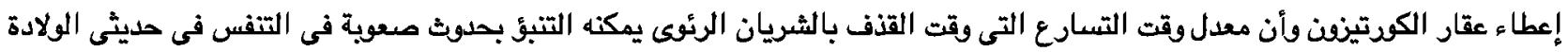
بشكل دقيق.

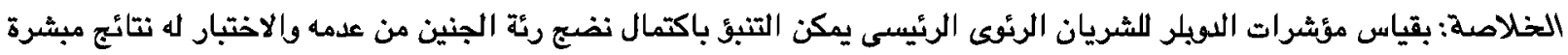

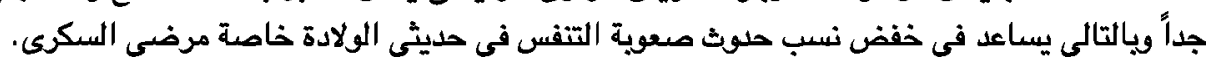

